Annuaire suisse de politique de développement

22-2 | 2003

Société de l'information et coopération internationale

\title{
La perspective d'un avenir meilleur pour tous
}

\section{Walter Fust}

\section{OpenEdition}

Journals

Édition électronique

URL : http://journals.openedition.org/aspd/501

DOI : 10.4000/aspd.501

ISSN : 1663-9669

Éditeur

Institut de hautes études internationales et du développement

Édition imprimée

Date de publication : 1 novembre 2003

Pagination : XIII

ISSN : 1660-5934

Référence électronique

Walter Fust, "La perspective d'un avenir meilleur pour tous », Annuaire suisse de politique de

développement [En ligne], 22-2 | 2003, mis en ligne le 16 mars 2010, consulté le 23 septembre 2020 URL : http://journals.openedition.org/aspd/501 ; DOI : https://doi.org/10.4000/aspd.501 


\section{La perspective d'un avenir meilleur pour tous}

a «révolution numérique» façonne la société de l'information du XXI siècle. Les technologies de l'information et de la communication (TIC) permettent de véhiculer des informations, des images et des sons en quelques fractions de seconde. La distance est annulée; ces canaux d'information permettent de communiquer interactivement.

Cette révolution concerne tous les aspects de notre vie: notre manière d'apprendre, de travailler et de communiquer. Elle touche également les interactions entre les gouvernements, les entreprises privées et la société civile.

La «révolution numérique» ouvre de nouvelles perspectives à ceux qui savent en tirer parti de manière efficace. D'autre part, elle risque d'exclure certains de ses bienfaits, d'aggraver les inégalités existantes et de creuser davantage le «fossé numérique» entre les personnes ayant accès aux TIC et celles qui en sont dépourvues.

Le «clivage numérique» correspond à un fossé social, culturel et politique plus profond. Voilà pourquoi l'expression «révolution numérique» ne reflète qu'une partie de la réalité. La «société mise en réseau» illustre les conséquences sociales de la «révolution numérique». Les améliorations substantielles de la technique de mise en réseau touchent les organisations sociales, culturelles, économiques et politiques. Il existe de nombreux exemples de partenariats entre plusieurs acteurs (multi-stakeholder partnerships) et de réseaux qui relient sur un pied d'égalité les gouvernements, la société civile et des partenaires du secteur privé dans un but d'interaction, d'échange des savoirs et de mesures communes.

Un partenaire au Bangladesh a comparé les TIC avec un couteau «à double tranchant»: un instrument précieux dans le quotidien et dans le ménage, mais qui détruit s'il est mal utilisé. Les TIC n'agissent pas «pour» ou «contre» le développement et l'atténuation de la pauvreté. En revanche, elles sont un instrument efficace pour transformer les informations en savoirs et contribuent à rendre les programmes de développement plus effectifs et plus efficaces. En outre, les TIC permettent de mobiliser de nouvelles ressources et de donner des impulsions au développement. Elles peuvent faciliter la communication interculturelle et, partant, améliorer la prévention des conflits.

L'intégration des TIC dans une vision vaste et une approche globale permet de créer un meilleur avenir pour tous.

Walter FUST

Directeur de la Direction du développement et de la coopération (DDC) et président du comité exécutif de Global Knowledge Partnership (GKP) 